\title{
A VIOLÊNCIA CONTRA A CRIANÇA E - ADOLESCENTE NA PERSPECTIVA DE AGENTES COMUNITÁRIOS DA SAÚDE
}

Sandra Adriana Neves Nunes

Rafael Siqueira de Guimarães

Fábio Jambeiro Santana Borges

Marcos Sales Maia

Manuella Lima Belo

Lais Ferreira Soares

Universidade Federal do Sul da Bahia (UFSB)

Bárbara Christian Magalhães da Silva

Rosana Maria de Carvalho Santos Barreto

Secretaria de Saúde/Prefeitura Municipal de Ilhéus
Recebido em: 02/04/2019

$1^{\text {a }}$ revisão em: 30/10/2019

Aceito em: 19/11/2019

\section{RESUMO}

A violência intrafamiliar é aquela praticada por familiares, constituindo-se em grave violação dos direitos da criança e do adolescente. O objetivo desse estudo foi investigar se Agentes Comunitários de Saúde (ACS) reconhecem sinais de violência intrafamiliar, se fazem notificação, se conhecem fatores de risco e proteção e se na sua formação receberam informações sobre essas temáticas. Participaram do estudo 119 ACS que responderam três questionários. Constatouse que os conhecimentos sobre sinais de violência, em especial, de violência sexual e psicológica, sobre notificação, sobre fatores de risco e proteção e sobre práticas parentais e habilidades sociais infantis deveriam fazer parte de cursos de capacitação dos ACS, bem como de toda a Equipe de Saúde, pelo fato de atuarem cotidianamente com as famílias no território. Conclui-se que os ACS não tiveram acesso aos conhecimentos produzidos pela psicologia do desenvolvimento infantil que poderiam orientar sua ação protetiva e preventiva junto às famílias.

Palavras-chave: violência intrafamiliar; agentes comunitários de saúde; fatores de risco e proteção. 


\title{
VIOLENCE AGAINST CHILDREN AND ADOLESCENTS IN THE PERSPECTIVE OF COMMUNITY HEALTH AGENTS
}

\begin{abstract}
Domestic violence is normally practiced by relatives, constituted in serious violation of the rights of the child and the adolescent. The objective of this study was to investigate whether Community Health Agents (CHA) recognize signs of intra-family violence, if they make the notification, if they know risk and protection factors and if in their training they received information about these issues. A total of 119 ACS respond to three questionnaires. We found that knowledge about signs of violence, especially sexual and psychological violence, about notification, about risk and protection factors, and about parental practices and children's social skills should be part of CHA training courses, as well as the Health Team, because they work with families on a daily basis. It is concluded that the ACS did not have access to the knowledge produced by the child development psychology that could guide their protective and preventive action with the families.
\end{abstract}

Keywords: domestic violence; community health agents; risk and protection factors. 


\section{LA VIOLENCIA CONTRA EL NIÑO Y EL ADOLESCENTE EN LA PERSPECTIVA DE AGENTES COMUNITARIOS DE LA SALUD}

\section{RESUMEN}

La violencia intrafamiliar es aquella practicada por familiares, constituido en grave violación de los derechos del niño y del adolescente. El objetivo de este estudio fue investigar si los Agentes Comunitarios de Salud (ACS) reconocen señales de violencia intrafamiliar, se hacen notificación, si conocen factores de riesgo y protección y si en su formación recibieron informaciones sobre esas temáticas. En este estudio 119 ACS respondieran a tres cuestionarios. Se constató que los conocimientos sobre señales de violencia, en especial, de violencia sexual y psicológica, notificación, factores de riesgo y protección, prácticas parentales y habilidades sociales infantiles deberían formar parte de cursos de capacitación de los ACS, así como de todo el equipo de salud, por el hecho de actuaren cotidianamente con las familias. Se concluye que los ACS no tuvieron acceso a los conocimientos da psicología del desarrollo que podrían orientar su acción proyectiva y preventiva junto a las familias.

Palabras clave: violencia intrafamiliar; agentes comunitarios de salud; factores de riesgo y protección. 


\section{INTRODUÇÃO}

A despeito de todas as recomendações, normas e resoluções nacionais e internacionais que tratam dos direitos das crianças e dos adolescentes, convivemos diariamente com notícias de graves violações praticadas, na maioria das vezes, pelas pessoas ou instituições que têm a responsabilidade de proteger sua vida e sua integridade física e promover sua saúde e bem estar psicológico. De acordo com documento recente, publicado pelo Ministério dos Direitos Humanos - MDH (2018) e intitulado "Letalidade infanto-juvenil: Dados da violência e políticas públicas existentes", no grupo etário entre 16 e 17 anos foi registrado um total de 8.153 mortes no ano de 2013, sendo $73,6 \%$ devidas às causas externas. De fato, o cenário de violência tem se agravado exponencialmente nas últimas quatro décadas; entre 1980 e 2013 os homicídios de adolescentes nessa faixa etária tiveram um aumento de 640,9\%.

Considerando as regiões, a Nordeste apresenta a maior incidência de violência letal contra adolescentes no país, com um índice de 5,97 para cada 1.000. Estimase, assim, que 16.180 adolescentes poderão ser assassinados até 2019 nessa região. A Bahia ocupa a $2^{a}$ posição no Brasil em taxa de homicídio de crianças e adolescentes e Itabuna, cidade vizinha a Ilhéus, foi considerada a cidade mais violenta para adolescentes, com 17 assassinatos para cada 1000 adolescentes $(\mathrm{MDH}, 2018)$. Ilhéus também se encontra entre os municípios baianos com alta incidência de violência contra adolescentes, com um índice de homicídios de adolescentes contido na faixa de 3-5 assassinados por cada 1000 adolescentes (Oliveira, 2009). Muitas crianças também morrem vítimas de negligência, por quedas, causas mecânicas, afogamento, eletricidade, fogo, etc. Ilhéus, em 2010, ocupava a $23^{a}$ posição no país, por essas causas de morte, com uma taxa de 17.5 por 100 mil habitantes.

De acordo com o Ministério Público do Estado da Bahia - MPBA (2014), no que se refere à violência sexual, o número de denúncias tem crescido consideravelmente no estado. Em 2005, foram registradas 225 denúncias no disque 100. Até 2014, o número de denúncias já chegava a 3.443 (somando-se o ano de 2013 e o mês de janeiro de 2014). As maiores incidências de denúncias nos últimos anos estão nos municípios de Salvador, Feira de Santana, Itabuna, Camaçari, Ilhéus, Porto Seguro, Vitória da Conquista, Simões Filho, Lauro de Freitas, Alagoinhas e Teixeira de Freitas.

De acordo com o Estatuto da Criança e do Adolescente (ECA), a violência intrafamiliar contra a criança e o adolescente é aquela praticada por seus familiares, constituindo-se em grave violação dos seus direitos, pois nega o direito à liberdade, à dignidade, ao respeito e à oportunidade de crescer e desenvolver-se em ambiente saudável e harmonioso (Presidência da República, 1990). A violência pode ser de natureza física (como tapas, beliscões, chutes e arremessos de objetos, o que pode causar lesões, traumas, queimaduras e mutilações), psicológica (rejeição, depreciação, discriminação, desrespeito, 
cobrança exagerada, punições humilhantes e utilização da criança ou do adolescente para atender às necessidades psíquicas de outros), sexual (estupro, incesto, assédio sexual, exploração sexual, pornografia, pedofilia, manipulação de órgãos sexuais, imposição de intimidades, exibicionismo, jogos sexuais e práticas eróticas não consentidas e impostas e "voyeurismo") e negligência (privação de comida, medicamentos; de omissão no atendimento à saúde e à educação; de descuido com a higiene; de falta de estímulo, de proteção contra as condições climáticas, enfim, de descaso à atenção necessária para o desenvolvimento físico, psíquico, moral e espiritual) (Ministério da Saúde, 2004). Vale ressaltar que uma criança ou um adolescente pode ser afetado por mais de um tipo ou natureza de violência, o que aumenta sua vulnerabilidade social.

De acordo com Malta, Bernal, Teixeira, Silva e Freitas (2017), a violência contra criança pode ser vista como um problema global, de impacto devastador e profundo para a vítima, familiares e sociedade. A atenção integral à criança e ao adolescente em situação de violência exige, antes de mais nada, a sensibilização de todos os profissionais do serviço de saúde. O profissional de saúde é o agente capaz de identificar uma situação de violência ou as condições que indicam que ela pode vir a ocorrer. Ao se deparar com os riscos, pode atuar no sentido de romper ou evitar dinâmicas abusivas. Assim, a ação do profissional diante da situação de violência pode representar uma oportunidade única de mudança de trajetórias de vidas.

A atenção primária à saúde é o primeiro nível de atenção do sistema de saúde. É a porta de entrada preferencial do Sistema Único de Saúde (SUS), na qual estão incluídos os cuidados essenciais de promoção, proteção, reabilitação e manutenção da saúde, prevenção de agravos, diagnóstico e tratamento dos problemas de saúde mais comuns e relevantes da população (Ministério da Saúde, 2010a). O Agente Comunitário de Saúde (ACS) é visto como o elementochave da equipe de saúde que trabalha na atenção primária de saúde, na medida em que ele é o elo entre a comunidade e os serviços (Gomes, Cotta, Cherchiglia, Mitre, \& Batista, 2009; Silva \& Rodrigues, 2000).

Alguns estudos conduzidos com ACS, com objetivo de compreender como eles vislumbram a situação de violência intrafamiliar em seus territórios, foram publicados no Brasil, nos últimos 10 anos. Palmezoni e Miranda (2011) verificaram a identificação da violência intrafamiliar contra crianças e adolescentes pelos ACS, em Minas Gerais. Eles concluíram que a negligência e o abandono foram citados por $62 \%$ dos entrevistados, $60 \%$ já diagnosticaram algum caso de violência, sendo que $50 \%$ deles já reconheceram de 1 a 5 casos. Um total de $42 \%$ encaminhou o caso para um membro da equipe e $19 \%$ não notificaram por medo de algum familiar do violentado descobrir. A ficha de notificação de violência nunca foi apresentada a $94 \%$ dos participantes, $84 \%$ nunca receberam um treinamento sobre o assunto e $54 \%$ se consideram capazes de realizar a identificação. Os autores concluem que é necessário um melhor treinamento dos 
ACS para que haja uma diminuição da subnotificação dos casos de violência em todo país.

Garbin, Melo, Molmomaz, Garbin e Rovida (2014) investigaram o nível de conhecimento e atitude do ACS diante da suspeição, detecção e notificação de casos de violência familiar numa amostra de 48 ACS das Equipes de Saúde da Família (ESF) de um município de pequeno porte paulista. Eles concluíram que a violência intrafamiliar é um fenômeno bastante comum nas localidades onde trabalhavam, sendo apontada por $71 \%$ dos ACS. Interessantemente, $73 \%$ dos ACS não se sentiam responsáveis pela notificação dos casos, ainda que $77 \%$ sentiam que deviam tomar alguma providência a respeito. Os autores concluem que o trabalho do ACS é deficiente quanto ao conhecimento para a detecção e a adoção de conduta adequada nos casos de violência intrafamiliar. Nesse sentido eles sugerem que o tema violência intrafamiliar seja incorporado nas estratégias de educação permanente.

Num estudo conduzido na Bahia, por Machado, Rodrigues, Vilela e Simões (2014) em três unidades de saúde da família do município de Jequié/BA, com 25 profissionais das ESF, incluindo os ACS, objetivou-se conhecer os tipos de violência intrafamiliar identificados pelos profissionais das equipes da ESF e descrever as suas principais estratégias de intervenção. Os resultados evidenciaram a identificação pelos profissionais das ESF da negligência e violência física e psicológica contra crianças. Os profissionais das ESF apoiam as famílias no reconhecimento da violência, propiciando a escuta, orientações e encaminhamento aos órgãos competentes, apesar de encontrarem algumas dificuldades nesse processo, como a falta de articulação mais efetiva com os órgãos de proteção e assistência às vítimas. De acordo com os autores, para uma atuação integral e para promoverem a prevenção e combate à violência intrafamiliar as ESF devem agregar a rede de serviços especializados das áreas da saúde, social, de segurança e justiça e da comunidade.

Num estudo realizado no interior de São Paulo, Giusto (2011) investigou, dentre outras coisas, o nível de conhecimento dos ACS em relação aos fatores de risco e proteção do desenvolvimento infantil relacionados à violência intrafamiliar. A autora concluiu que os ACS acertaram em média $80,63 \%$ das questões, indicando um bom nível de conhecimento sobre esses fatores. Além disso, a pesquisadora também investigou o percentual de identificação ou suspeita dos casos de violência física, psicológica, sexual e negligência contra a criança e o adolescente. Ela conclui que $60 \%$ dos entrevistados suspeitaram pelo menos uma vez ou mais de uma vez de casos de violência física durante sua rotina de trabalho. No que diz respeito à violência sexual, um percentual ainda maior $(66,7 \%)$ suspeitou uma ou mais de uma vez de sua ocorrência. Já com relação à violência psicológica e negligência, o percentual foi de $66,7 \%$ e $73,4 \%$, respectivamente. Finalmente, a autora encontrou um percentual alto de ACS (60\%) que afirmou que não fez, nem faria a notificação dos casos de violência. O motivo para a não notificação foi não saber como proceder $(57,14 \%)$ nos casos de violência física, sexual e psicológica. 
No caso de negligência, o mesmo percentual reportou medo de prejudicar a vítima.

Finalmente, Maia, Ferrari, Gabani, Tacla, Reis e Fernandes (2016), numa pesquisa que buscou conhecer o cotidiano de profissionais do serviço de atenção primária de saúde frente aos casos de violência contra a criança, levantaram informações junto a 66 ACS, dentre outros profissionais, e concluíram que os profissionais entrevistados consideram que a proximidade com a comunidade, a disponibilidade de agenda e a equipe multiprofissional são fatores que os auxiliam a lidar com a violência. Por outro lado, alguns profissionais relataram dificuldades, como o medo de ser vítima do agressor, a forma de abordar a criança maltratada e a sua família.

A despeito de haver muitos estudos que investiguem as crenças de ACS sobre a violência contra criança e o adolescente, ainda são poucos os estudos conduzidos no nordeste e, especificamente, na Bahia. Também foi encontrado apenas um estudo que investigou se os ACS reconhecem os fatores de risco e proteção do desenvolvimento infantil relacionados à violência intrafamiliar (Giusto, 2011), mas conduzido no interior de São Paulo. Além disso, a maioria dos estudos encontrados foi de natureza qualitativa, apoiando-se em amostras bastante pequenas.

Considerando a escassez de estudos sobre o tema no estado da Bahia, que a maioria dos estudos tem empregado metodologias qualitativas e julgando relevante investigar, além da percepção e conhecimento dos ACS sobre sinais e sintomas de violência, sobre seus encaminhamentos e sobre sua formação, qual o seu nível de conhecimento sobre os fatores de risco e proteção do desenvolvimento infantil, esse estudo, de natureza quantitativa, visa preencher essa lacuna, o que justifica sua relevância. Assim, o estudo teve como objetivos investigar: i) se os ACS reconhecem os principais sinais e sintomas da violência física, psicológica, sexual e negligência contra criança e adolescente, ii) quais as primeiras ações no caso de identificação dos sinais de violência contra a criança e o adolescente, iii) se notificam os casos, em que serviço e quais os motivos para não-notificação, iv) se sabiam qual o papel do Conselho tutelar no atendimento dos casos de violência contra a criança e o adolescente e qual o retorno obtido após fazer a denúncia, v) se na formação profissional tiveram acesso a informações que o auxiliassem a fazer o encaminhamento adequado aos casos de violência e, finalmente, vi) se conhecem os fatores de risco e proteção do desenvolvimento infantil e outras temáticas concernentes à Psicologia do desenvolvimento que podem servir de base para as ações protetivas e preventivas junto às crianças, adolescentes e suas famílias.

\section{MÉTODO}


Trata-se de um estudo quantitativo, descritivo e exploratório. O estudo replicou a metodologia, incluindo o uso dos mesmos instrumentos, da pesquisa conduzida por Giusto (2011) em sua dissertação de mestrado.

\section{PARTICIPANTES}

Participaram do estudo 119 ACS que atuavam em 18 ESF e 06 PACS do município de Ilhéus, BA. Os critérios de inclusão para a participação do estudo foram: a) ser ACS das UBS do Bairro Nossa Senhora da Vitória, b) Desenvolver atividades no território de abrangência, c) ser maior de 18 anos, d) não estar afastado de suas funções por motivo de saúde, férias ou outros.

\section{INSTRUMENTOS}

Os instrumentos utilizados para a coleta de dados foram:

1) Questionário sociodemográfico: O questionário continha sete perguntas relativas ao sexo, idade, raça/etnia, estado civil, nível de escolaridade, renda familiar e renda per capita, com a finalidade de caracterizar a amostra.

2) Questionário de Avaliação de Conhecimento sobre Fatores de Risco e Proteção (Q.A.C.): Desenvolvido por Silva (2004), o instrumento é composto por 32 questões fechadas do tipo verdadeiro e falso, referentes a fatores de risco e a fatores de proteção ao desenvolvimento infantil referentes à violência intrafamiliar. Tem como objetivo medir o conhecimento dos participantes sobre a identificação de tais fatores. Basicamente, nesse questionário são apresentadas afirmações corretas e incorretas e é solicitado ao participante que indique se a afirmação é verdadeira ou falsa. $O$ instrumento não foi submetido a procedimentos de validação. Esse questionário foi construído por Silva (2004), em sua pesquisa de mestrado tendo como base na revisão bibliográfica que utilizou referências de autores especialistas em desenvolvimento infantil, tais como Bee (1995), Brino (2002), CRAMI (2000), Guralnick (1998), Holden, Geffner e Jouriles (1998), Rutter (1985), Hutz (2002), Monteiro e Phebo (1997b), Ontario Ministry of Community and Social Services (2001), Era-Grant, Thomas, Offord, Boyle, Werner (1998) e Windon (1989) (ver Silva, 2004, p. 49). Em sua fase de elaboração, o questionário foi submetido à avaliação de um juiz (um profissional especialista no tema), que sugeriu apenas pequenas modificações (Silva, 2004). No presente estudo, foi analisada a consistência interna do instrumento e foram obtidos valores abaixo do aceitável para todas as dimensões (Dimensão Fator de Proteção - Verdadeiro, $\alpha=0,086$; Dimensão Fator de Proteção - Falso, $\alpha=0,119$, Dimensão Fator de Risco - Verdadeiro, $\alpha=0,311$; Dimensão Fator de Risco Falso, $\alpha=0,381$ ).

3) Questionário sobre violência intrafamiliar contra crianças e adolescentes: Desenvolvido por Rossi (2004), o questionário traz uma definição do conceito de cada modalidade de violência: violência física, sexual, psicológica e negligência e em seguida objetiva-se identificar se o participante já atendeu (ou pelo menos 
suspeitou) a algum caso de violência contra a criança e adolescente em sua rotina de trabalho, bem como quais encaminhamentos fez a partir disso (se notificou ou notificaria, com que conversaria, quais os motivos para a não notificação, etc.). Há também um espaço no final, caso o participante queira se manifestar. Portanto, esse questionário não é um instrumento que mede constructos psicológicos, dispensando a necessidade de estudos de investigação das propriedades psicométricas para precisar validade e confiabilidade.

\section{PROCEDIMENTO}

Inicialmente foi feito o contato junto a Coordenação da Atenção Básica do Município de Ilhéus visando levantar as informações necessárias sobre o município. Nesse momento, a carta de anuência foi solicitada à coordenação da Atenção. Uma vez obtida à carta de anuência, o projeto foi submetido ao Comitê de Ética (CEP), via Plataforma Brasil, que foi aprovado sob o parecer número, 1.841.777, em 29/11/2016.

Após a aprovação no CEP, a equipe de pesquisadores entrou em contato com todas as enfermeiras responsáveis pelas Unidades de Saúde ou ESF para apresentar em linhas gerais a pesquisa, destacar os aspectos éticos envolvidos, esclarecer dúvidas e agendar o horário e dia para reunir os ACS nas respectivas Unidades. Na ocasião do encontro agendado com os ACS, foi obtido o Termo Consentimento Livre e Esclarecido (TCLE) e foram aplicados os questionários àqueles que aceitaram participar do estudo. O estudo realizado por Giusto (2011) realizou a aplicação impressa dos instrumentos, entretanto, neste estudo foi decidido, por conta do número de participantes e facilidade de organização dos dados coletados, que questionários estariam disponíveis em uma plataforma online (https://www.onlinepesquisa.com/) que era acessada pelos pesquisadores em notebooks, tablets ou celulares que individualmente direcionavam as questões aos participantes. Em algumas ocasiões em que houve problema de acesso à internet, uma versão física dos questionários era aplicada, individual ou coletivamente, em pequenos grupos, na presença do pesquisador. A duração da sessão de aplicação de questionários foi em torno de 60 a 90 minutos para cada participante, sendo realizada em um único encontro.

\section{ANÁLISE ESTATÍSTICA}

Foi empregada a estatística descritiva para análise dos dados, através da média e desvio-padrão. Além disso, foram geradas figuras e tabelas para sumarizar dados descritivos, como números de casos e porcentagens. Os dados coletados foram analisados e sumarizados por meio do Programa Excel.

\section{RESULTADOS}

Dos 119 ACS, 50,9\% atuavam em ESF e 49,1\% em PACS, sendo a maioria do sexo feminino, casados, com idade superior a 40 anos, com nível de escolaridade 
média e com renda per capita de no máximo um salário mínimo. A Tabela 1 apresenta as principais características sociodemográficas dos participantes.

Quando solicitados a responder se atendiam em sua rotina de trabalho crianças e adolescentes, 109 (95,6\%) afirmaram que atendiam a crianças de 0 a 4 anos, 107 (93,9\%) atendiam crianças com idades entre 5 e 9 anos, 105 (92,1\%) crianças e adolescentes com idades entre 10 e 14 anos e 95 (83,3\%) atendiam adolescentes com idades entre 15 e 19 anos.

Quando solicitados a responder quais os sinais que chamariam a atenção e poderiam indicar que uma criança ou adolescente está sofrendo violência física doméstica, 84 ACS (70,58\%) citaram a presença de hematomas, 25 (21\%) citaram sinais atuais de lesão, machucados, beliscões, inchaços, arranhaduras ou edemas. Fratura e queimaduras também foram lembradas por seis (5\%) e 13 participantes (10,9\%), respectivamente. Além disso, 90 ACS (75,6\%) reportaram sinais comportamentais e psicológicos que imaginam estar relacionados à violência física, tais como mudanças de comportamento (isolamento social, agressividade, irritabilidade, criança muito calada, agitação, timidez) e emocionais (medo, tristeza, depressão). Finalmente, seis ACS (5,0\%) informaram que não sabiam responder ou deixaram essa pergunta em branco

Quanto aos sinais de violência sexual, 90 ACS $(75,6 \%)$ indicaram como sinais desse tipo de violência as alterações de comportamentos (isolamento social, agressividade, vergonha) e os sinais emocionais (medo, apatia e tristeza). Apenas 12 participantes $(9,2 \%)$ indicaram que a exibição de comportamento sexualizado precoce seria um sinal possível de indicar violência sexual e dois lembraram que a criança pode exibir medo ou resistência em ser tocada (1,7\%). Um total de 10 ACS $(8,4 \%)$ afirmou que é possível identificar sinais de violência apenas quando a criança os expressa por meio de palavras, desenhos ou contrai infecções sexualmente transmissíveis ou mesmo engravida. Finalmente, sete ACS $(5,9 \%)$ informaram que não sabiam responder ou deixaram a pergunta em branco.

No que se refere aos sinais de violência psicológica, $87(73,1 \%)$ respondentes indicaram vários problemas de comportamento internalizantes (medo, timidez excessiva, insegurança, isolamento, depressão ou tristeza), como seus principais sinais e $37(31,1 \%)$ indicaram problemas externalizantes, como agressividade, recusa a ir à escola, baixo rendimento escolar, uso de drogas e prostituição. Nove $\operatorname{ACS}(7,6 \%)$ informaram que não sabiam responder ou deixaram a pergunta em branco. 
Tabela 1

Características sociodemográficas do agente comunitário de saúde (ACS) que atuam no município de Ilhéus, BA

\begin{tabular}{|c|c|c|c|}
\hline Variável & $\mathbf{n}$ & $\%$ & Média (DP) ou Moda \\
\hline \multicolumn{4}{|l|}{ Sexo } \\
\hline Masculino & 23 & 19,3 & \\
\hline Feminino & 93 & 78,2 & \\
\hline \multicolumn{4}{|l|}{ Idade } \\
\hline$\leq 40$ anos & 20 & 16,8 & $M=48,58(7,69)$ \\
\hline$\geq 41$ anos & 96 & 80,7 & \\
\hline \multicolumn{4}{|l|}{ Estado civil } \\
\hline Casado & 50 & 42,0 & \multirow[t]{5}{*}{ Moda $=$ Casado } \\
\hline Separado & 13 & 10,9 & \\
\hline judicialmente/divorciado & 46 & 38,7 & \\
\hline Solteiro & 6 & 5,0 & \\
\hline Viúvo & & & \\
\hline \multicolumn{4}{|l|}{ Nível de escolaridade } \\
\hline Ens. Fund. Incompleto & 2 & 1,7 & \multirow{8}{*}{$\begin{array}{c}\text { Moda = Ensino médio } \\
\text { Completo }\end{array}$} \\
\hline Ens. Fund. Completo & 6 & 5,0 & \\
\hline Ensino Médio Incompleto & 5 & 4,2 & \\
\hline Ensino Médio Completo & 75 & 63,0 & \\
\hline Ensino Sup. Incompleto & 10 & 8,4 & \\
\hline Ensino Sup. Completo & 6 & 5,0 & \\
\hline Pós-Grad. Incompleto & 3 & 2,5 & \\
\hline Pós-Grad. Completo & 8 & 6,7 & \\
\hline \multicolumn{4}{|l|}{ Renda per capita } \\
\hline Até um salário mínimo & 86 & 72,3 & \multirow{4}{*}{$\begin{array}{c}\text { Moda }=\text { Até um salário } \\
\text { mínimo }\end{array}$} \\
\hline Entre 1,5 e 3 sal. mínimos & 29 & 24,4 & \\
\hline Entre 3,5 e 5 sal. mínimos & 0 & 0,0 & \\
\hline Entre 5,5 e 7 sal. mínimos & 0 & 0,0 & \\
\hline \multicolumn{4}{|l|}{ Renda familiar } \\
\hline Até um salário mínimo & 45 & 37,8 & \multirow{4}{*}{$\begin{array}{c}\text { Moda = Entre } 1,5 \text { e } 3 \\
\text { salários mínimos }\end{array}$} \\
\hline Entre 1,5 e 3 sal. mínimos & 60 & 50,4 & \\
\hline Entre 3,5 e 5 sal. mínimos & 7 & 5,9 & \\
\hline Entre 5,5 e 7 sal. mínimos & 3 & 2,5 & \\
\hline
\end{tabular}


Tabela 1

\section{Continuação}

\section{Variável}

Número de pessoas com quem divide a casa

Uma a duas pessoas

Três a quatro pessoas

Cinco a seis pessoas

Mais de seis pessoas n

\section{$\%$}

Média (DP) ou Moda

Finalmente, no que diz respeito aos sinais de negligência, 34 (28,6\%) participantes reportaram que a falta de higiene é sinal de negligência e 32 $(26,9 \%)$ indicam os sinais de desnutrição. 25 (19,3\%) ACS relataram o fato de crianças e adolescentes serem deixadas sozinhas em casa ou, então, nas ruas, por muito tempo como sinal de negligência. Apenas sete participantes $(5,9 \%)$ lembram que a baixa frequência ou a retirada da criança da escola pode ser um sinal de negligência familiar. Finalmente, 12 ACS $(10,1 \%)$ afirmaram que não sabia responder ou deixaram a pergunta em branco.

Ao todo, 47 ACS (39,5\%), dos 116 que responderam a questão, suspeitaram ou presenciaram violência física contra a criança e o adolescente em sua rotina de trabalho, mas, desses, 36 (78,3\%) não notificaram. Suas ações mais imediatas foram conversar com o chefe imediato $(38,3 \%)$, conversar com a mãe $(27,7 \%)$ ou com o pai da vítima (21,3\%). Dos 11 participantes (21,7\%) que fizeram a notificação, cinco $(45,4 \%)$ fizeram ao conselho tutelar, três $(27,3 \%)$ ao CRAS do Bairro, um $(9,1 \%)$ à vigilância epidemiológica, um $(9,1 \%)$ ao NASF e um $(9,1 \%)$ ao serviço social do Projeto que acontece no bairro. Oito deles (80\%) afirmam que acompanharam a situação da vítima após a notificação, mas três informam que acham que cumpriram sua função ao notificar o caso.

Dentre os que não notificaram, apenas 33 responderam a questão sobre os motivos para a não-notificação e as respostas estão apresentadas na Figura 1: 


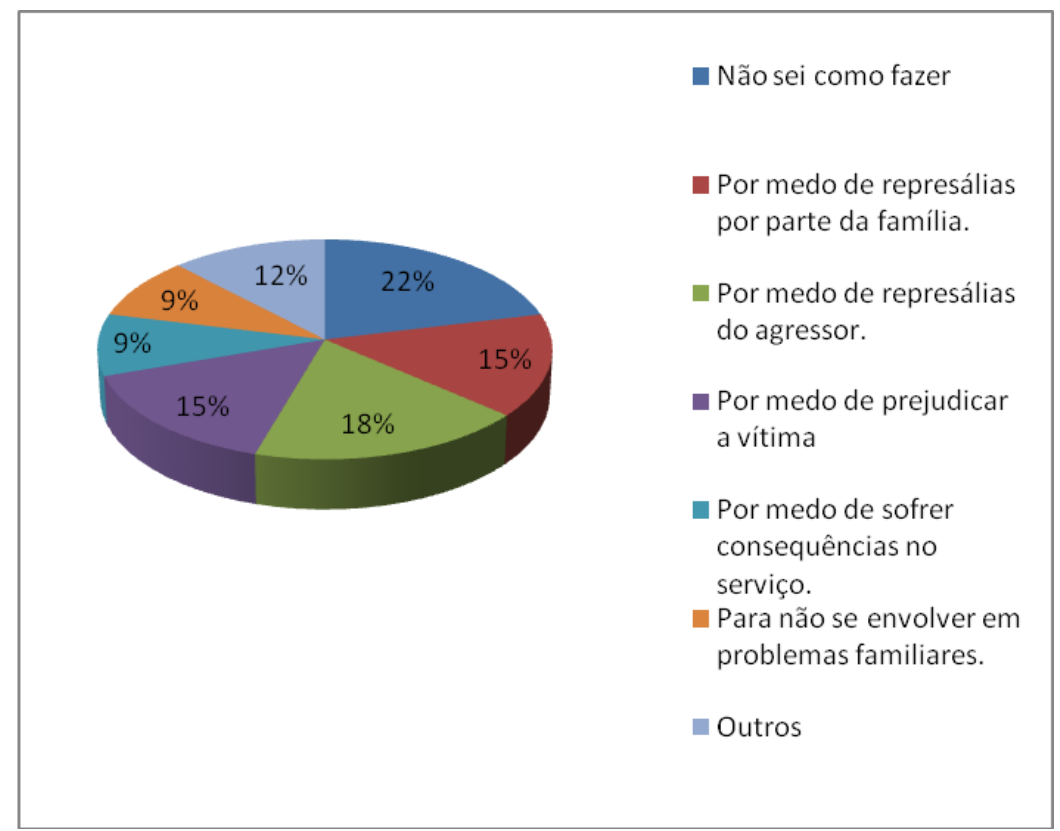

\section{Figura 1}

Motivos indicados pelos ACS para não terem feito a notificação dos casos suspeitos ou presenciados de violência física contra a criança ou adolescente.

Quando perguntados se notificariam, caso suspeitassem ou presenciassem casos de violência física contra a criança e o adolescente em sua rotina de trabalho, apenas 84 ACS responderam (70,6\%). Desses que responderam, apenas 18 $(21,4 \%)$ afirmaram que notificariam. Novamente, os participantes responderam que não notificariam porque não sabem como proceder (35\%), por medo de represálias do agressor (20\%), por medo de represálias da família $(17,5 \%)$, ou para não se envolver com problemas da família (10\%)

No que diz respeito à violência sexual, dos 113 respondentes, 89 (78,8\%) afirmaram que nunca suspeitaram esse tipo de violência em sua rotina de trabalho. Dos 24 que suspeitaram pelo menos uma vez, 10 (41,7\%) não fizeram a notificação. Dos 14 que fizeram, cinco $(35,7 \%)$ fizeram a denúncia ao conselho tutelar, um $(7,1 \%)$ procurou o serviço social de um projeto desenvolvido na comunidade, dois (14,3\%) procuram o CRAS, um (7,1\%) procurou o Ministério Público, um $(7,1 \%)$ procurou a polícia, dois (14,3\%) disseram que a própria família fez a denúncia e um $(7,1 \%)$ fez a notificação na própria unidade de saúde. Dentre os que notificaram, $12(85,7 \%)$ acompanharam a vítima e dois (14,3\%) acharam que haviam cumprido sua função. As principais ações imediatamente tomadas após a suspeita de violência sexual foram: conversar com a mãe da vítima (52\%), com o chefe imediato (40\%) ou com o pai da vítima (12\%). Os motivos para não terem feito a notificação estão distribuídos na Figura 2. 


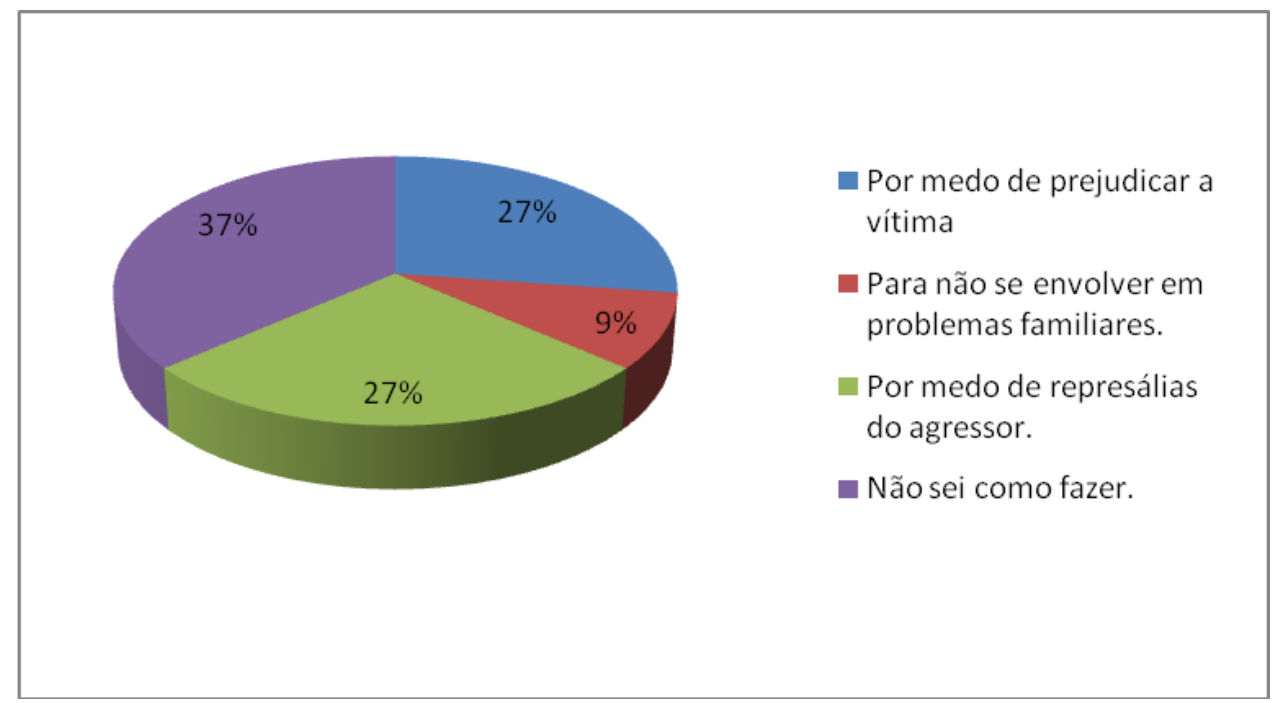

\section{Figura 2}

Motivos indicados pelos ACS para não terem feito a notificação dos casos suspeitos de violência sexual contra a criança ou adolescente.

Quando perguntados se notificariam, caso suspeitassem de casos de violência sexual contra a criança e o adolescente em sua rotina de trabalho, apenas 96 ACS responderam (80,7\%). Desses que responderam, 36 (37,5\%) afirmaram que não notificariam. Novamente, os participantes responderam que não notificariam porque não sabem como proceder $(25,6 \%)$, por medo de represálias do agressor (20,5\%), por medo de represálias da família $(23,1 \%)$, ou por medo de prejudicar a vítima (15,4\%).

Dos 116 participantes que responderam as perguntas sobre ocorrência de violência psicológica contra a criança e o adolescente na rotina de trabalho, 60 $(53,1 \%)$ afirmaram que nunca suspeitaram ou presenciaram esse tipo de violência. Dos 56 que suspeitaram ou presenciaram, 45 (84,9\%) não notificaram. As principais ações tomadas diante da suspeita ou da observação desse tipo de violência foram: conversar com a mãe da vítima (68,5\%), conversar com o pai da vítima $(22,2 \%)$ e conversar com o chefe imediato $(22,25)$ e conversar com um colega de trabalho (13\%). Dos 11 que fizeram a notificação, cinco $(45,45)$ levaram a denúncia ao conselho tutelar, um ao serviço social do projeto desenvolvido na comunidade, um ao CAPS e um ao NASF. Dos que notificaram, seis (40\%) acompanharam a situação da vítima e cinco $(33,4 \%)$ acharam que tinham cumprido com sua obrigação ao notificar.

Quando solicitados a indicar os motivos para a não notificação, 44 dos 45 que não notificaram responderam, conforme a Figura 3. 


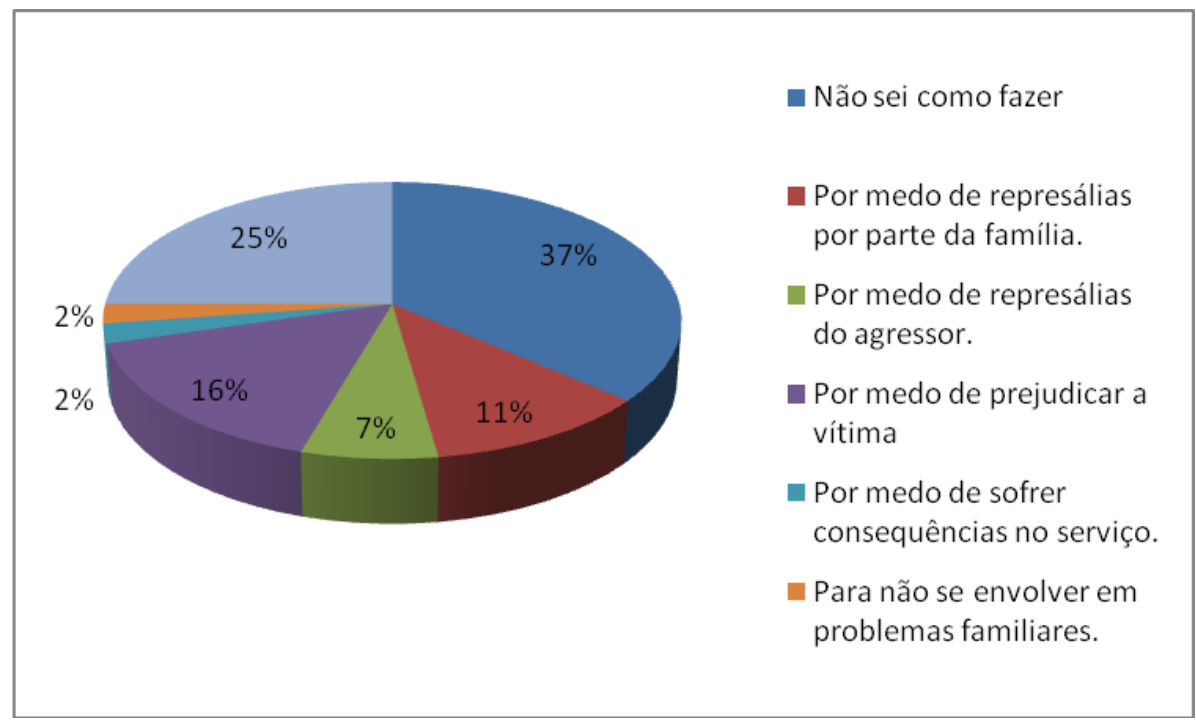

\section{Figura 3}

Motivos indicados pelos ACS para não terem feito a notificação dos casos suspeitos de violência psicológica contra a criança ou adolescente.

Quando perguntados se notificariam, caso suspeitassem de casos de violência psicológica contra a criança e o adolescente em sua rotina de trabalho, apenas 74 ACS responderam (62,2\%). Desses que responderam, 36 (48,6\%) afirmaram que não notificariam. Novamente, os participantes responderam que não notificariam porque não sabem como proceder $(35,1 \%)$, por medo de represálias do agressor (24,3\%), por medo de represálias da família (13,5\%), para não sofrer consequências no serviço $(10,85)$ ou por medo de prejudicar a vítima $(5,4 \%)$.

Finalmente, no que diz respeito à negligência, dos 115 respondentes, 57 $(49,6 \% \%)$ afirmaram que nunca suspeitaram desse tipo de violência em sua rotina de trabalho. Dos 58 que suspeitaram pelo menos uma vez, 40 (69\%) não fizeram a notificação. Dos 18 que fizeram, cinco (27,8\%) levaram a denúncia ao conselho tutelar, três $(16,7 \%)$ ao CRAS, um $(5,6 \%)$ ao serviço social do Projeto, um $(5,6 \%)$ ao NASF e um (5,6\%) ao hospital. Dentre os que notificaram, 10 (55,6\%) acompanharam a vítima e seis $(33,4 \%)$ acharam que haviam cumprido sua função. As principais ações imediatamente tomadas após a suspeita de violência sexual foram: conversar com a mãe da vítima $(40,7 \%)$, com o chefe imediato $(57,6 \%)$ ou com o pai da vítima (22\%). Os motivos para não terem feito a notificação estão distribuídos na Figura 4. 


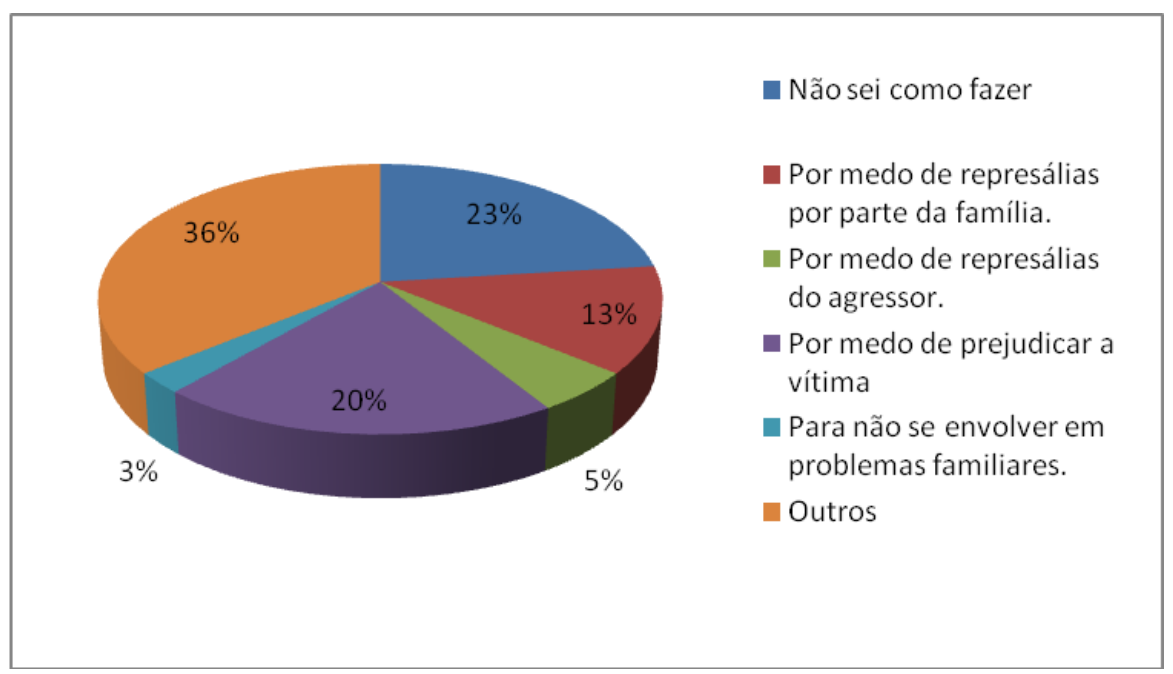

\section{Figura 4}

Motivos indicados pelos ACS para não terem feito a notificação dos casos suspeitos de negligência contra a criança ou adolescente.

Quando perguntados se notificariam, caso suspeitassem de casos de negligência contra a criança e o adolescente em sua rotina de trabalho, apenas 68 ACS responderam (57,1\%). Desses que responderam, 33 (48,5\%) afirmaram que não notificariam. Novamente, os participantes responderam que não notificariam por medo de represálias do agressor (16,1\%), por medo de represálias da família (16,1\%), para não sofrer consequências no serviço $(9,7 \%)$ ou por medo de prejudicar a vítima $(9,7 \%)$.

Com relação ao papel do Conselho Tutelar frente à denúncia dos casos de violência, 36 participantes lembraram que a função é de investigar a procedência e veracidade dos casos e apenas nove lembraram que uma de suas funções e fazer a notificação, acatando a denúncia. 30 ACS atribuíram funções bastantes gerais ao Conselho tutelar como proteger, acompanhar ou acolher os casos de violência. Apenas cinco lembraram que uma das funções do Conselho tutelar é encaminhar os casos mais graves, que configuram crime, ao ministério público ou outros órgãos competentes. 15 dos participantes afirmaram não saber ou preferiram não opinar nessa pergunta.

Aos 119 participantes foi perguntado qual o tipo de retorno recebido, no caso de terem feito a denúncia de violência de qualquer tipo contra a criança e o adolescente. Dos 70 ACS que responderam a essa pergunta, 23 (32,9\%) indicaram que não foram atendidos e $18(25,7 \%)$ responderam que o resultado não atendeu as suas expectativas. Além disso, apenas $10 \%$ afirmaram que foram atendidos imediatamente.

Foi perguntado aos participantes se na sua formação profissional eles tiveram acesso a discussões sobre sua responsabilidade de denúncia dos casos de violência contra acriança e o adolescente. Dos 114 ACS que responderam essa 
questão, 56 (49,1\%) afirmaram que sim, 27 (23,7\%) afirmaram que não, e 31 $(27,2 \%)$ afirmaram que não lembravam ou não saberiam dizer.

Para avaliar se os participantes conheciam o conceito de fatores de risco e proteção, bem como se sabiam identificá-los no seu cotidiano, foi empregado um instrumento que trazia afirmações corretas ou equivocadas sobre o tema e para as quais o ACS deveria indicar se tratava-se de informação verdadeira ou falsa. Observou-se que 20,2\% dos participantes desconheciam o conceito de fatores de proteção, como condições ou variáveis que diminuem a probabilidade de o indivíduo desenvolver problemas de desenvolvimento. Quando apresentado o conceito de fatores de risco, como condições ou variáveis que estão associados à alta probabilidade de ocorrência de resultados negativos ou indesejáveis, como comportamentos que podem comprometer a saúde, o bem-estar ou o desempenho social do indivíduo, 7,1\% dos participantes também desconheciam o conceito.

Para 8,8\% dos participantes, o abusador sexual é geralmente alguém estranho à criança e a sua família. Um total de $13,4 \%$ não achou que a família pode ser destacada como responsável pela socialização da criança. Além disso, 32,7\% dos participantes concordam que, independente das circunstâncias, ninguém pode perceber quando a criança está sendo vítima de violência em sua própria casa e $66,1 \%$ concordam que o fato de a criança conhecer técnicas para se autoproteger e resolver problemas em situações difíceis não minimizaria a ocorrência de situações negativas como a violência sexual. Um percentual alto (67\%) dos participantes discordou que os fatores de proteção, por si só, garantem um bom desenvolvimento da criança, $8 \%$ discordam que regras familiares claras sejam fator de proteção do desenvolvimento e 12,5\% discordam que instituições que forneçam tratamento para o abuso de substâncias como álcool e drogas e apoio para os familiares constitui-se em fator de proteção e desenvolvimento infantil. Finalmente, 29,5\% concordam que a violência física, praticada dentro do lar, que leva à fatalidade é um evento raro, não sendo responsável por um número excessivo de mortes no Brasil.

\section{DISCUSSÃO}

De modo geral, os ACS parecem reconhecer corretamente os sinais de violência física, citando os hematomas, os sinais de lesões atuais (como arranhaduras, machucados, beliscões, por exemplo) e as queimaduras como principais exemplos. Esses sinais também foram indicados pelos ACS investigados por Giusto (2011) e estão em concordância com o Manual de Segurança da Criança e do Adolescente da Sociedade Brasileira de Pediatria (Pfeiffer; Waksman, 2004) e pelo Manual de Medicina Legal (França, 2008). De acordo com esses Manuais, lesões em dorso, órgãos genitais e nádegas de crianças são raramente decorrentes de acidentes. Para Lopez e Campos Júnior (2007) as queimaduras são relativamente comuns, ocorrendo em cerca de $10 \%$ das crianças que sofreram violência física. As fraturas de ossos, por outro lado, foram lembradas por apenas 
seis ACS, mas Pfeiffer e Waksman (2004) informam que elas ocupam o segundo lugar na classificação de prevalência dos casos.

Os sinais comportamentais e psicológicos associados à violência física foram bastante lembrados pelos ACS no presente estudo, especialmente as alterações comportamentais e emocionais internalizantes (isolamento social, timidez, tristeza, depressão) e externalizantes (agressividade, irritabilidade, agitação). Tais alterações, de fato podem representar sinais de que a criança está sendo vítima de violência física no ambiente familiar. A esse respeito, Paiva e Zaher (2012) alertam que a investigação dos casos de violência deve começar pelo olhar atento da atitude da criança, pelo profissional de saúde, durante a avaliação. De acordo com o autor, posturas temerosas, defensivas, apáticas ou tristes devem ser vistas como sinais de alerta, principalmente quando associadas a fatores de risco do desenvolvimento.

No que diz respeito aos sinais de violência sexual, os ACS que participaram desse estudo, em sua grande maioria, indicaram os mesmos tipos de alterações emocionais e os comportamentos internalizantes (isolamento social, vergonha, medo, apatia e tristeza) e externalizantes (agressividade) indicados na violência física. Muito poucos (apenas 12 participantes) indicaram que a exibição de comportamento sexualizado precoce seria um importante sinal violência sexual. De fato, Williams (2002) relata que dentre os sinais de violência sexual estão o medo, isolamento social e o choro e, também, a agressividade, mas é importante lembrar que a presença isolada desses indicadores psicológicos não é suficiente para a interpretação de abuso sexual, uma vez que podem estar relacionados a outras formas de violências e maus tratos. Por outro lado, a Cartilha do Ministério Público do Distrito Federal e Territórios (MPDFT, 2015) e o Manual do Ministério da Saúde "Linha de cuidado para a atenção integral à saúde de crianças e adolescentes e suas famílias em situação de violência" (Brasil, 2010a) orientam que os sinais mais comuns de violência sexual contra a criança são: curiosidade sexual excessiva, exposição frequente dos genitais, brinquedos ou jogos sexualizados, agressividade sexual, masturbação excessiva, conhecimento sexual inapropriado para a idade, além de doenças sexualmente transmissíveis, infecções urinárias repetidas e gravidez. A dificuldade dos ACS reconhecerem sinais específicos de abuso sexual na infância é um fato alarmante, uma vez que esse tipo de violência quando passada despercebida pode levar a graves desdobramentos na vida presente e futura da vítima (Özkara, 2004). De acordo com a Organização Mundial da Saúde (WHO, 1999), as consequências do abuso sexual na infância são profundas, incluindo transtornos psíquicos, prostituição, transtornos sexuais, depressão e suicídio na vida adulta.

Por ser um evento mais silencioso e difícil de medir, os sinais comportamentais e emocionais de violência psicológica, tendem a ser os mais difíceis de reconhecer. De acordo com a National Society for the Prevention of Cruelty to Children (NSPCC), os sinais podem variar entre exibição de comportamentos como chupar dedo, arrancar cabelos, balançar o corpo repetidamente, ser 
incapaz de brincar, apresentar medo excessivo de cometer erros, apresentar problemas de fala súbitos, exibir sinais de automutilação, expressar medo de que os pais sejam procurados para falar do seu comportamento, apresentar atrasos no desenvolvimento emocional e até no crescimento (NSPCC, 2009). Entre os participantes no presente estudo, foram lembrados apenas os sinais psicológicos mais generalizados, que podem estar presentes em outras foram de violência (problemas internalizantes e externalizantes).

Finalmente, os sinais físicos de negligência infanto-juvenil foram os mais facilmente reconhecidas pelos ACS, com destaque para a falta de higiene, baixo peso e desnutrição e abandono. Esses sinais também foram apontados pelos ACS do estudo de Giusto (2011) e estão em concordância com os dados nacionais e internacionais, como os da NSPCC (2009), do Manual da Sociedade Brasileira de Pediatria de Pfeiffer e Waksman (2004) e achados de Lopez e Campos Júnior (2007). No entanto, poucos ACS nesse estudo reportaram a baixa frequência escolar como um sinal de negligência educacional (Lopez \& Campos Júnior, 2007; Perry, Colwell, \& Schick, 2002) e um percentual considerável não soube indicar os sinais desse tipo de violência.

É interessante notar, que independentemente do tipo de violência, os participantes desse estudo tenderam a lembrar mais de alterações emocionais e comportamentais que a criança ou o adolescente exibe, fato que também ocorreu no estudo de Ramos e Silva (2011) conduzido com ACS em São Paulo. Além disso, eles tiveram mais facilidade em reconhecer os sinais de violência física e de negligência, que estão entre as formas de violência mais notificadas no Brasil. Num estudo que analisou as notificações de violências contra crianças entre 0 a 9 anos, no ano de 2011, registradas pelos serviços públicos de saúde no Brasil, utilizando os dados do Sistema da Vigilância de Violências e Acidentes (Viva/SINAN), os autores concluíram que dos tipos de violência notificadas, as predominantes foram a negligência ( $n=7.716 ; 47,5 \%)$, seguidas das violências física ( $n=5.969,38,5 \%)$, sexual $(n=5.675,37 \%)$ e psicológica/moral $(n=3.772$; 25,2\%) (Rates, Melo, Mascarenhas, \& Malta, 2015).

Apesar de saberem identificar os principais sinais de violência física e de quase $40 \%$ ter presenciado ou suspeitado de casos em sua rotina de trabalho, a maioria dos ACS (78,3\%) não fez a notificação. Além disso, quase a metade dos que responderam (aproximadamente 47\%) já suspeitou ou presenciou violência psicológica na sua rotina de trabalho, mas $85 \%$ deles não notificaram. Também, aproximadamente $50 \%$ dos participantes suspeitaram de negligência infantojuvenil, mas quase $70 \%$ não notificaram. Finalmente, um percentual menor $(21,2 \%)$, mas relevante, suspeitou de casos de violência sexual, sendo que quase $42 \%$ desses não fizeram a notificação dos casos. Esses resultados corroboram com os achados de Giusto (2011), que encontrou um percentual relativamente alto de ACS (60\%) que não fizeram nem fariam a notificação dos casos de violência 
A negligência infanto-juvenil, como se pode notar, foi a mais observada na rotina de trabalho dos ACS, seguida pela violência psicológica, pela violência física e pela violência sexual, resultado que corrobora com Maia et al. (2016), num estudo conduzido no Paraná, com 180 profissionais de saúde, sendo 66 deles ACS. Para os autores, os ACS, técnicos/auxiliares de enfermagem e enfermeiros foram os que mais atenderam os casos de violência, sendo as mais comuns negligência e abandono (43,3\%), abuso psicológico (22,8\%), abuso físico (20\%) e abuso sexual (16,1\%). Da mesma forma, Palmezoni e Miranda (2011) realizaram uma pesquisa com ACS em Minas Gerais e concluíram que a negligência e o abandono foi o mais citado, alcançando $62 \%$ dos entrevistados. Num estudo de revisão sistemática, os autores concluíram que há predomínio da negligência (50\%), seguindo pela violência física $(33,3 \%)$, psicológica $(8,3 \%)$ e sexual $(8,3)$ (Nunes \& Sales, 2016).

Como é possível observar nos resultados do presente estudo, houve subnotificação para todos os tipos de violência. De fato, apenas a violência sexual teve notificação que ultrapassou os $50 \%$. Além disso, quando perguntados se notificariam, caso suspeitassem ou presenciassem casos de violência física, sexual, psicológica ou negligência no futuro, um percentual entre 19,3 e 42,9\% preferiram não responder à questão. No caso da violência física, dentre os que responderam, a maioria (quase $80 \%$ ) afirmou que não notificaria. Quanto à violência sexual, dentre os que responderam, um percentual considerável $(37,5 \%)$ também afirmou que não notificaria. No que se refere à violência psicológica, quase $50 \%$ afirmou que não notificaria. Finalmente, com relação à negligência, dentre os que responderam também aproximadamente a metade afirmou que não notificaria. Esses resultados corroboram com o que tem sido encontrado em vários estudos que incluem profissionais de saúde da Atenção Básica e, especificamente, ACS. Garbin et al. (2014), por exemplo, investigaram os conhecimentos e atitudes de 48 ACS diante da suspeição, detecção e notificação de casos de violência intrafamiliar. Eles concluíram que apesar da identificação de violência familiar ser apontada por $71 \%$ dos ACS, $73 \%$ deles não se sentiam responsáveis pela notificação dos casos. O estudo de Machado et al. (2014), os ACS entrevistados revelaram dificuldades nesse processo de notificação, em virtude da falta de articulação mais efetiva com os órgãos de proteção e assistência às vítimas. Palmezoni e Miranda (2011) reportaram que dentre os ACS entrevistados em seu estudo, 94\% afirmaram que a ficha de notificação de violência nunca lhes foi apresentada e $84 \%$ afirmam que nunca receberam um treinamento sobre o assunto. Lima et al. (2011), em seu estudo conduzido também no interior da Bahia, concluíram que, embora $82,7 \%$ dos profissionais de saúde tenham reconhecido que o enfrentamento da violência seria também responsabilidade do Setor Saúde, entre aqueles que suspeitaram ou identificaram, a notificação foi feita por apenas $17,8 \%$ pelo próprio profissional. Para os Profissionais da ESF a mãe foi vista a figura mais destacada para fazer a notificação. Assim, a subnotificação parece ser uma realidade presente no Brasil (Garbin, Dias, Rovida, \& Garbin, 2015; Giusto, 2011). 
Vale lembrar que de acordo com o ECA (1990), os Setores de Saúde e de Educação constituem-se como esferas privilegiadas de proteção, com a competência de notificar as situações de violência, como um dos elementos de busca de soluções para proteger a vítima da situação de violência e apoiar os familiares. O Estatuto confere obrigatoriedade não apenas aos médicos, mas a todos os profissionais de saúde, de notificar às autoridades competentes os casos (suspeitos ou confirmados), sendo inclusive prevista uma multa de três a vinte salários de referência para os casos que se omitirem. Além disso, o ato de notificar dá início a um processo que leva a interromper a situação de violência no âmbito familiar (Luna, Ferreira, \& Vieira, 2010).

Os motivos para a não notificação encontrados nesse estudo são bastante conhecidos pela literatura. Os profissionais sentem mais expostos por morarem no mesmo território da vítima e temem represálias do agressor (Andrade et al., 2011; Maia, et al., 2016) e da família (Palmezoni \& Miranda, 2011; Ramos \& Silva, 2011). Muitos profissionais afirmaram que não sabem como proceder para notificar e mais da metade afirmou que não recebeu ou não lembra se recebeu capacitação que lhe orientasse a fazer a notificação. Essa percepção de despreparo dos profissionais de saúde, especialmente dos ACS, para atender e notificar os casos de violência contra a criança e adolescente já foi referida em inúmeros estudos (Andrade et al., 2011; Garbin et al., 2014; Giusto, 2011; Maia et al., 2016; Palmezoni \& Miranda, 2011).

Quanto às ações imediatas tomadas diante da suspeita de violência, as preferenciais foram falar ao chefe imediato, conversar com a mãe e, por último, com o pai da vítima, no caso da violência física e negligência, ou conversar com a mãe da vítima em primeiro lugar, seguida de conversar com o chefe imediato, no caso de violência sexual e psicológica. De acordo com esse dado, os ACS tendem a buscar seus chefes para ter orientação sobre como proceder, resultado também encontrado no estudo de Giusto (2011). Eles também reportam que buscam falar com as mães, porque as julgam mais responsáveis pela criação dos filhos do que os pais (Nunes \& Sales, 2016) ou porque nos casos de violência sexual o companheiro da mãe ou o próprio pai são os agressores.

No que diz respeito ao local para fazer a notificação, a maioria dos participantes indicam que o Conselho Tutelar seria o órgão mais indicado para receber as notificações. Esse resultado também foi encontrado no estudo de Giusto (2011). Tal resultado está em acordo com o ECA (1990), que atribui aos Conselhos Tutelares a função defender e garantir os direitos das crianças e adolescentes, detendo ainda o poder de aplicar medidas de atendimento e responsabilização ou encaminhar os casos mais graves para o ministério público, quando necessário.

Para finalizar, nos últimos anos, o número de estudos que investiga os efeitos dos fatores de risco e proteção no desenvolvimento infanto-juvenil tem aumentado muito. Os fatores de proteção dizem respeito às influências ou condições de 
desenvolvimento que otimizam ou melhoram as respostas pessoais a determinados riscos de desenvolvimento. Os fatores de risco, por sua vez, dizem respeito a acontecimentos negativos ao longo do desenvolvimento que ampliam as possibilidades de o indivíduo apresentar problemas emocionais, físicos ou sociais futuros (Poletto \& Koller, 2008). As fortes evidências científicas de que os fatores de risco e proteção influenciam negativa ou positivamente o desenvolvimento infantil levaram esse tema a ser foco de atenção de organismos internacionais importantes, tais como o Banco Mundial (BM), o Banco Interamericano de Desenvolvimento (BID), a Comissão Econômica para a América Latina e o Caribe (CEPAL), o Programa das Nações Unidas para o Desenvolvimento (PNUD) e a Organização das Nações Unidas para a Educação, Ciência e Cultura (UNESCO).

A despeito da importância do tema para qualquer profissional de saúde que atende crianças e adolescentes em sua rotina de trabalho, observou-se nesse estudo que um percentual considerável de ACS desconhece os conceitos de fatores de risco $(20,2 \%)$ e proteção $(7,1 \%)$ do desenvolvimento. Cerca de $1 / 3$ dos participantes pensam que seja impossível perceber quando a criança está sendo vítima de violência em sua própria casa. Além disso, para a maioria deles (quase $70 \%$ ) os fatores de proteção não são capazes, por si só, de garantir um bom desenvolvimento da criança.

Quase $10 \%$ dos participantes desconhecem que o abusador é normalmente alguém da própria família da vítima. Notavelmente, um percentual importante (em torno de 30\%) concorda que a violência física intrafamiliar grave, que leva à fatalidade, seja um evento raro, não sendo responsável por um número excessivo de mortes de crianças no Brasil. Tais resultados vão ao encontro das estatísticas apresentas por documentos oficiais que tratam da violência contra a criança e o adolescente no Brasil (MDH, 2018). Portanto, no Brasil, a violência física grave, que leva à morte infanto-juvenil, está se tornando um evento progressivamente comum e um problema relevante de saúde pública. Vale lembrar que as cartilhas e documentos do Ministério da Saúde e do Ministério Público Federal que tratam do enfrentamento da violência contra a criança (Brasil, 2010a; MPDFT, 2015) têm divulgado que a violência física letal é um fato, infelizmente, bastante frequente no Brasil e que o abusador geralmente é membro da família, normalmente o companheiro da mãe.

Um fator de proteção do desenvolvido bastante reconhecido na literatura psicológica diz respeito ao desenvolvimento de habilidades sociais infantis. Assim, o fato de a criança conhecer técnicas para se autoproteger e resolver problemas em situações difíceis (como procurar um adulto de confiança para relatar algum comportamento sexualmente inapropriado por parte de um adulto) tende a minimizar a ocorrência da violência sexual, por exemplo. Aproximadamente $2 / 3$ dos ACS não concordam que essa habilidade social infantil de se autoproteger e resolver problemas em situações difíceis seja um fator de proteção na infância. Para Del Prette e Del Prette (2005), o desenvolvimento da 
competência Social da criança deve ser examinada com vistas à promoção da qualidade de vida e à prevenção de problemas na infância e adolescência.

Outro conhecimento bastante disseminado entre psicólogos do desenvolvimento infantil é que a família é a instituição que exerce papel central nos primeiros anos de socialização e que o emprego de práticas educativas parentais consistentes, com regras claras de comportamento, constitui-se com fator de proteção do desenvolvimento infantil (Baumrind, 1971). Novamente, apesar de se constituírem como conhecimentos bastante elementares da Psicologia do Desenvolvimento, em torno de $10 \%$ dos ACS demonstram não ter tido acesso a eles. O desenvolvimento de ações que promovam a capacitação de famílias protetivas tem sido apontado como medida importante pelos pesquisadores em saúde da família (Pinheiro, Haase, Del Prette, Amarante, \& Del Prette, 2015) e de políticas públicas no campo da atenção básica (Santos \& Yakuwa, 2015).

A esse respeito, cabe uma reflexão acerca do papel do psicólogo nos Núcleos de Apoio à Saúde da Família (NASF). Os NASF têm a função de ampliar a abrangência e o escopo das ações da Atenção Básica, fornecendo suporte à ESF (Portaria MS n. 154, de 24 de janeiro de 2008). Sua principal ferramenta de trabalho é o apoio matricial às equipes de saúde da família de um território (Ministério da Saúde, 2010b). Centra-se em nove áreas estratégicas, dentre as quais se destaca a saúde mental, em virtude da alta prevalência dos transtornos mentais.

Se considerarmos a realidade específica do contexto sul-baiano, é a primeira vez que se realiza um estudo desta natureza junto à politica de Atenção Básica no que tange a este tema. Novos estudos, com base nestes dados, podem ser realizados, bem como as devolutivas do mesmo podem ser incorporadas nas políticas municipais, tendo em vista o desenvolvimento de intervenção junto a ACS e toda a equipe do NASF, considerando as demandas levantadas por este estudo.

\section{CONSIDERAÇõES FINAIS}

Para que a atenção à saúde à criança e ao adolescente ocorra de fato de maneira integral são necessárias práticas interdisciplinares por meio do compartilhamento dos conhecimentos produzidos por todas as áreas da saúde, entre os profissionais que atuam no sistema. Observou-se nesse estudo, que os conhecimentos sobre sinais de violência, em especial, de violência sexual e psicológica, que são as menos conhecidas, sobre a responsabilidade do profissional de saúde em notificar os casos suspeitos ou detectados, sobre como fazer a notificação, sobre fatores de risco e proteção do desenvolvimento e sobre práticas parentais e habilidades sociais infantis deveriam fazer parte de cursos de capacitação dos ACS, bem como de toda a Equipe de Saúde, pelo fato de esses profissionais atuarem direta e cotidianamente com as famílias e com as crianças na Atenção Básica e serem co-responsáveis pela sua proteção. Parece 
fundamental que os conhecimentos produzidos pela psicologia do desenvolvimento infantil sirvam de fundamento para a ação protetiva e preventiva da ESF, em especial dos ACS, junto às crianças, adolescentes e suas famílias.

Além disso, para que as ações de prevenção e combate à violência intrafamiliar dos profissionais de saúde, incluindo os ACS, sejam efetivas, é necessário que a elas sejam articuladas em rede, não apenas envolvendo serviços especializados das áreas da saúde, mas também, da rede intersetorial, com os serviços de assistência social, de segurança e de justiça e da comunidade numa atenção integral da vítima.

Finalmente, a despeito de ter atingido seus objetivos, esse estudo apresenta algumas limitações importantes. Em primeiro lugar, a amostra foi composta de apenas ACS, dentre os profissionais que compõem as Equipes da ESF. Em segundo lugar, foi apenas empregada a estatística descritiva para a análise dos dados. Finalmente, foi empregada uma escala não validada (Questionário de Avaliação de Conhecimento sobre Fatores de Risco e Proteção), de cujas dimensões obtiveram-se níveis de consistência interna não aceitáveis nesse estudo. Assim, recomenda-se que estudos futuros incluam todos os profissionais que compõem as Equipes de ESF para que seja possível uma visão mais ampla do fenômeno e que incorporem objetivos que envolvam análises inferenciais, de modo que torne a pesquisa metodologicamente mais robusta. Por fim, recomenda-se que os resultados referentes à escala não validada para o Brasil sejam considerados com cautela e que futuros estudos tomem o cuidado de empregar apenas escalas já validadas e confiáveis.

\section{REFERÊNCIAS}

Andrade E. M, Nakamura E., Paula C. S, Nascimento R., Bordin I. A,. \& Martin D. (2011). A visão dos profissionais de saúde em relação à violência doméstica contra crianças e adolescentes: Um estudo qualitativo. Saúde e Sociedade, 20(1), 147-155. doi: 10.1590/S010412902011000100017

Baumrind, D. (1971). Current patterns of parental authority. Developmental Psychology Monoghraph, 4, 1-103. doi: 10.1037/h0030372

Del Prete, Z. A., \& Del Prete. (2005). A Psicologia das habilidades sociais na infância: Teoria e prática. Petrópolis, RJ: Vozes.

Garbin C. A., Dias I. A., Rovida T. A., \& Garbin A. J. (2015). Desafıos do profıssional de saúde na notifıcação da violência: Obrigatoriedade, efetivação e encaminhamento. Ciências \& Saúde Coletiva, 20(6), 1879-90. doi: 10.1590/1413-81232015206.13442014

Garbin, C. A., Melo, L. M., Moimaz, S. A., Garbin, A. J., \& Rovida, T. A. (2014). Violência intrafamiliar na rotina do agente comunitário de saúde. Journal of Health Science Institute, 32(4), 385-9.

Giusto, R. O. (2011). Agentes comunitários de Saúde e sua concepção sobre família e violência. (Dissertação de Mestrado). Universidade Federal de São Carlos, São Carlos.

Gomes, K. D., Cotta, R. M., Cherchiglia, M. L., Mitre, S. M., \& Batista, R. S. (2009). A práxis do agente comunitário de saúde no contexto do programa saúde da família: Reflexões estratégicas. Saúde e Sociedade, 18(4), 744-755. doi: 10.1590/S0104-12902009000400017

Lima, M. C., Costa, M. C., Bigras, M., Santana, M. A., Alves, T. D., Nascimento, O.C., \& Silva, M. R. (2011). Atuação profissional da atenção básica de saúde face à identificação e notificação da violência infanto-juvenil. Revista Baiana de Saúde Pública, 35(Supl 1), 118-137.

Lopez, F. A, \& Campos Júnior D. (2007). Tratado de pediatria. São Paulo, SP: Manole. 
Luna G. L, Ferreira R. C, \& Vieira L. J. (2010). Notificação de maus tratos em crianças e adolescentes por profissionais de saúde da Equipe Saúde da Família. Ciências \& Saúde Coletiva, 15(2), 481-91. doi: 10.1590/S1413-81232010000200025

Machado, J. C., Rodrigues, V. P., Vilela, A. B. A., Simões, A. V., Morais, R. L., \& Rocha, E. N. (2014). Violência intrafamiliar e as estratégias de atuação da equipe de Saúde da Família. Saúde \& Sociedade, 23(3), 828-840. doi: 10.1590/S0104-12902014000300008

Maia, J. N., Ferrari, R. A., Gabani, F. L., Tacla, M. T., Reis, T. B., \& Fernandes, M. L. (2016). Violência contra criança: Cotidiano de profissionais na atenção primária à saúde. Revista Rene, 17(5), 593-601. doi: 10.15253/rev\%20rene.v17i5.6179

Malta, D. C., Bernal, R. T. I., Teixeira, B. S .M., Silva, M. M. A., \& Freitas, M. I. F. (2017). Fatores associados a violências contra crianças em serviços sentinela de urgência nas capitais brasileiras. Ciências \& Saúde Coletiva, 22(9), 2889-2898. doi: 10.1590/141381232017229.12752017

Ministério da Saúde. (2004). Violência faz mal à saúde. Brasília, DF: Ministério da Saúde.

Ministério da Saúde. (2010a). Linha de cuidado para a atenção integral à saúde de crianças, adolescentes e suas famílias em situação de violências. Brasília, DF: Secretaria de Atenção à Saúde, Departamento de Ações Programáticas e Estratégicas.

Ministério da Saúde. (2010b). Diretrizes do NASF: Núcleo de Apoio a Saúde da Família. Brasília, DF.

Ministério dos Direitos Humanos. Secretaria Nacional de Proteção dos Direitos da Criança e Adolescente. (2018). Letalidade infanto-juvenil: dados da violência e políticas públicas existentes / elaboração de Thaís Cristina Alves Passos - Documento eletrônico. Brasília, DF: Ministério dos Direitos Humanos.

Ministério Público do Distrito Federal e Territórios. (2015). Violência Sexual contra crianças e adolescentes: Identificação e enfrentamento. Núcleo de Enfrentamento à Violência e à Exploração Sexual de Crianças e Adolescentes, Sede do MPDFT, Brasília-DF.

Ministério Público do Estado da Bahia - MPBA. (2014). MP lança nova campanha de combate à violência sexual contra crianças e adolescentes. Recuperado de https://www.mpba.mp.br/noticia/28658

National Society for the Prevention of Cruelty to Children (NSPCC). (2009). Definition and signs of child abuse. Child Protection Fact Sheet.

Nunes, A. J., \& Sales, M. C. V. (2016). Violência contra crianças no cenário brasileiro. Ciência \& Saúde Coletiva, 21(3), 871-88. doi: 10.1590/1413-81232015213.08182014

Oliveira, C. S. (2009). Índice de homicídios na adolescência: Análise dos homicídios em 267 municípios brasileiros com mais de 100 mil habitantes (Relatório de Pesquisa). Secretaria Especial dos Direitos Humanos - SEDH, Subsecretaria Nacional de Promoção dos Direitos da Criança e do Adolescente - SNPDCA, Fundo das Nações Unidas para a Infância - UNICEF, Observatório de Favelas Laboratório de Análise da Violência (LAV/UERJ).

Özkara E., Karatosun, V., Gunal, I., \& Oral, R. (2004). Trans-metatarsal amputation as a complication of child sexual abuse. Journal of Clinical Forensic Medicine 11(3), 129-132. doi: 10.1016/j.jcfm.2004.01.011

Paiva C., \& Zaher V. L. (2012). Violência contra crianças: O atendimento médico e o atendimento pericial. Saúde, Ética \& Justiça, 17(1), 12-20.

Palmezoni, V. P., \& Miranda, F.J. S. (2011). A identificação da violência intrafamiliar contra crianças e adolescentes pelo agente comunitário de saúde. Saúde Coletiva, 8(49), 88-92.

Perry, B., Colwell, K., \& Schick, S. (2002). Child Neglect. Encyclopedia of Crime and Punishment, 1, 192-196. doi: 10.4135/9781412950664

Pfeiffer, L., \& Waksman, R. D. (2004). Violência na infância e adolescência. Manual de segurança da criança e do adolescente. São Paulo, SP: Sociedade Brasileira de Pediatria/Nestlé Nutrição.

Pinheiro, M. I. S. Haase, V. G., Del Prette, A., Amarante, C. L. D., \& Del Prette, Z. A. P. (2006). Treinamento de habilidades sociais educativas para pais de crianças com problemas de comportamento. Psicologia Reflexão \& Crítica, 19(3), 407-414. doi: 10.1590/S010279722006000300009

Poletto, M., \& Koller, S. (2008). Contextos ecológicos: Promotores de resiliência, fatores de risco e de proteção. Estudos de Psicologia, 25(3), 405-416. doi: 10.1590/S0103166X2008000300009

Presidência da República. Casa Civil. Subchefia para Assuntos Jurídicos. (1990). Lei no 8.069, de 13 de julho de 1990: Dispõe sobre o Estatuto da Criança e do Adolescente e dá outras providências. DOU de 16/07/1990. Brasília, DF. 
Ramos M. L. C. O., \& Silva A. L. (2011). Estudo sobre a violência doméstica contra a criança em unidades básicas de saúde do município de São Paulo-Brasil. Saúde e Sociedade, 20(1)، 136-46. doi: 10.1590/S0104-12902011000100016

Rates, S. M., Melo, E. M., Mascarenhas, \& M. D., Malta, D. C. (2011). Violência infantil: Uma análise das notificações compulsórias. Ciência e saúde coletiva, 20(3), 655-665. doi: 10.1590/141381232015203.15242014

Rossi, D. (2004). Notificação da violência doméstica contra crianças e adolescentes: Procedimento de profissionais de saúde do setor público de Campinas - SP. (Tese de Doutorado). Universidade Estadual de Campinas, Campinas.

Santos, J. S., \& Yakuwa, M. S. (2015). A Estratégia Saúde da Família frente à violência contra crianças: Revisão integrativa. Revista Sociedade Brasileira de Enfermagem Pediátrica, 15(1), 38-43.

Silva, J. M. da (2004). Capacitação de conselheiros tutelares: Instruir para aprimorar. (Dissertação de Mestrado). Universidade Federal de São Carlos, São Carlos.

Silva M. J, \& Rodrigues R. M. (2000). O agente comunitário de saúde no processo de municipalização da saúde. Revista Eletrônica de Enfermagem, 2(1). doi: 10.5216/ree.v2i1.678

Williams, L. C. (2002). Abuso sexual infantil. In , H. J. Guilhardi et al. (Eds.). Sobre comportamento e cognição: Contribuição para a construção da teoria do comportamento. Santo André, SP: ESETec, 7.

World Health Organization (WHO). (1999). WHO Consultation on Child Abuse Prevention. Geneva: WHO.

\section{AGRADECIMENTOS}

Os autores agradecem ao Ministério da Saúde, por meio do Programa PET Saúde-GraduaSUS, e à Universidade Federal do Sul da Bahia pela concessão de bolsas PET e de Iniciação Científica.

\section{CONFLITOS DE INTERESSES}

Não há conflitos de interesses.

\section{FINANCIAMENTO}

Pesquisa financiada pelo Ministério da Saúde, por meio do Programa PET Saúde-GraduaSUS, e pela Universidade Federal do Sul da Bahia.

\section{SOBRE OS AUTORES}

Sandra Adriana Neves Nunes é psicóloga pela Universidade Federal de Santa Catarina, mestre pela Universidade de Greenwich, Inglaterra, e doutora em Psicologia pela Universidade Federal de Santa Catarina. É Professora Adjunta da Universidade Federal do Sul da Bahia (UFSB) e recebeu Bolsa PET GraduaSUS, por ser coordenadora do Projeto PET, ao qual se vincula essa Pesquisa. E-mail: sandranunes@ufsb.edu.br

Rafael Siqueira de Guimarães é psicólogo pela Universidade Estadual Paulista, mestre pela Universidade Federal de São Carlos e doutor em Sociologia pela Universidade Estadual Paulista. É Professor Adjunto da Universidade Federal do Sul da Bahia (UFSB) e recebeu Bolsa PET GraduaSUS, por ser tutor do Projeto PET, ao qual se vincula essa Pesquisa. E-mail: rafasguimaraes@ufsb.edu.br

Fábio Jambeiro Santana Borges é graduado pelo Bacharelado Interdisciplinar em Saúde da Universidade Federal do Sul da Bahia. É estudante de Medicina da Universidade Federal do Sul da Bahia e foi estudante bolsista do PET GraduaSUS. E-mail: fabiojambeiroborges@gmail.com

Marcos Sales Maia é graduado pelo Bacharelado Interdisciplinar em Saúde da Universidade Federal do Sul da Bahia. É estudante de Medicina da Universidade Federal do Sul da Bahia e foi estudante bolsista do PET GraduaSUS. E-mail: marcossalesmaia@gmail.com 
Manuella Lima Belo é graduada pelo Bacharelado Interdisciplinar em Saúde da Universidade Federal do Sul da Bahia e foi estudante bolsista de Iniciação Científica da UFSB. E-mail: manuellalima.belo@gmail.com

Laís Ferreira Soares é graduada pelo Bacharelado Interdisciplinar em Saúde da Universidade Federal do Sul da Bahia. É estudante de Medicina da Universidade Federal do Sul da Bahia e foi estudante bolsista de Iniciação Científica da UFSB. E-mail: laisf.soares@hotmail.com

Bárbara Christian Magalhães da Silva é enfermeira pela Universidade Estadual de Santa Cruz, especialista em Saúde Coletiva Habilitação em Sanitarista pela FTC e especialista em Saúde da Família com Ênfase na Implantação das Linhas do Cuidado pela Escola Estadual de Saúde Pública Prof. Francisco Peixoto de Magalhães Neto e Secretaria do Estado da Bahia. Recebeu Bolsa PET GraduaSUS, por ser preceptora do Projeto PET, ao qual se vincula essa Pesquisa. E-mail: bcmagalhaess@yahoo.com.br

Rosana Maria de Carvalho Santos Barreto é enfermeira pela Universidade Estadual de Santa Cruz e especialista em m Saúde Coletiva e Gestão em Saúde pela Escola Estadual saúde pública da Bahia. Recebeu Bolsa PET GraduaSUS, por ser preceptora do Projeto PET, ao qual se vincula essa Pesquisa. E-mail: roca barreto@hotmail.com 